\title{
GUEST EDITORIAL Evidence that stress per se has a role in the precipitation and natural history of depressive illness
}

Molecular Psychiatry (2013) 18, 954-956; doi:10.1038/mp.2013.85

Studies of the relationship between stress and the liability to depression involve the interposition of multiple factors, and not all findings are intuitive. As an example, contrary to expectation, Kendler et al., ${ }^{1,2}$ found that social context bears little relationship to the likelihood of responding to adversity with depression. In other instances, hard data validate intuitive judgments. Childhood sexual abuse objectively confers susceptibility to depressive illness. ${ }^{3}$ Unexpectedly, the type and duration of the stressor influence the phenotype of the depressive episode. The death of a significant other or the traumatic ending of a romantic relationship generally precipitates a melancholic-like depression while chronic stress in the absence of a specific trigger is generally associated with an atypical-like depression. ${ }^{4}$

To complicate matters, logical, believable reasons for depression do not always represent genuine causes. Kendler, et al. ${ }^{5}$ tested the hypothesis that patients whose depressions occur only in the context of significant stress have less genetic loading or childhood trauma than those whose depressions arise strictly out of the blue. As it turned out, both groups of patients have remarkably similar family histories of depression and early traumatic experiences. Kendler et $a l^{5}{ }^{5}$ termed the hypothesis that reasons equal causes, a 'hypothetical trap'. Thus, plausible reasons do not necessarily constitute unequivocal causes. Ultimately, Kendler et $a l^{6}{ }^{6}$ argued against a dichotomy between purely stress-induced and purely biologically mediated depressions, or combinations of the two alone. Rather, he proposed 11 categories of difference makers. These include molecular genetics, systems neuroscience, aggregate genetic effects, neuropsychological factors, personality and attitudinal factors, trauma exposure, as well as social, political and cultural factors. ${ }^{6}$

Despite the clear complexity of parsing out variables such as the roles of environmental stress, culture and attitudinal factors in the etiology of depression, it is not impossible to deduce the extent to which full-blown depressive episodes are associated with stressors validated by prior studies to lead to depression. In a recent issue of Molecular Psychiatry, Kendler and Halberstadt ${ }^{7}$ published a compelling and elegant paper entitled, 'The road not taken: life experiences in monozygotic twin pairs discordant for major depression.' The authors assembled 12 monozygotic twins reared together rigorously discordant for lifetime major depressive disorder (MDD). As monozygotic twins begin life with identical genotypes and are reared together in the same family, differences between them are most likely meaningful differences in environmental experiences. This study provides a unique opportunity to examine the ways in which environmental factors contribute to depressive illness that would be difficult to achieve by any other strategy.

The authors interviewed each twin pair together to provide a joint biography and to describe important differences in their life course that might provide environmental sources of their discordance for MDD. The stories of the 12 twin pairs served as the data for this publication. A valid environmental reason for the onset of major depression emerged in each of the affected twins.
Although the authors hoped that most pairs would reveal a single cause for the discordance for MDD, they found that the complexity of the life histories led instead to causal pathways that were nuanced and tentative.

Before reviewing these stories, I would like to comment on one striking point that was true of all but one twin pair. With this one exception, the identical twins remained exceedingly close to one another and were often each other's best friend. In these eleven pairs, the well twin offered no judgment about the affected twin's character and could suggest no weakness that they considered to be important in the affected twin's MDD. Several of the well twins stated that had he or she had the same history as their affected twin, they would have fully expected themselves to have developed MDD as well.

By far, the most common event that emerged prior to the development of MDD in the affected twin was the traumatic loss of an important romantic relationship. This was the case in 8 of the 12 histories. In five of the eight cases, moderate temperamental differences such as impulsivity, dependency and stimulus seeking may have contributed to early marriages that ended poorly. For most of these five individuals, losses of romantic partners happened to them repeatedly throughout their lives. This pattern could constitute a cumulative continuity arising when an individual's style of interaction channels him or her into environments that reinforce that style. This phenomenon subsequently sustains the behavior pattern across the life course through progressive accumulation of its own consequences.

In three pairs, an unhappy marriage occurred as a consequence of what seemed like bad luck. Each of these three twins with major depression had chosen seemingly appropriate spouses at a time when they were sufficiently mature to marry. They found the breakup of their marriages shattering.

A single event seemed to have constituted the precipitant for the MD in only two twin pairs. In one case, the single event was a traumatic brain injury incurred during adolescence that significantly reduced cognitive function throughout adult life. In the second case, a fatal motor vehicle accident that resulted in the death of a young mother of three children precipitated a major depressive episode. The affected twin reports that she has never been able to recover from her enormous guilt over this tragedy.

In two pairs, occupational stress resulted in the depressive illness of the affected twin. In one pair, a cautious twin studied library science and moved up slowly in the course of his stable career. The affected twin struck out on his own and started multiple businesses, each of which failed. In this case, the risk taking, venturesome twin was the one who developed depressive illness. In a second pair, one twin married after a long-term relationship and had a lengthy and stable marriage. The affected twin was much more ambitious, received a masters degree in divinity, and became the principal minister of her own church. She experienced great stress because of perceived bias towards female ministers, and states that she exposed herself to an environment that exceeded her capacity to bear stress. She credits this stress with precipitating her depression.

These data are compatible with the previous study of Kendler and Gardner $^{8}$ dealing with 72 pairs of female monozygotic twins discordant for MDD. The lifetime stressor 
most closely associated with the risk for MDD was a history of divorce (odds ratio 6.2). This study also supported the hypothesis of the continuity of stressors over time. The twin with depressive illness reported a greater number of total stressful events and higher rates of two classes of events, romantic problems and job loss.

Basic and clinical studies of depressive illness clearly support a role of stress in MDD. We first proposed that major depression reflects a dysregulation of the stress response, ${ }^{9-11}$ much like a dysregulation of the immune response leads to autoimmune disease. The stress system and depression share many common mediators and circuitries.

The acute stress response consists of anxiety, focused attention, activations of the CRH and sympathetic nervous systems, and inhibition of behaviors likely to be deleterious in threatening situations. These include sleep, sexual activity, eating, attention to pleasurable stimuli and the shifting of mood, all in the service of resisting non-adaptive distractions. ${ }^{9}$ There are also premonitory activations of responses that might be critical in the context of a possible injury occurring during threatening situations. During stress, individuals experience premonitory activations of inflammation ${ }^{12}$ in case of tissue injury, and of coagulation, ${ }^{13}$ as a defense against hemorrhage. To conserve energy, the activities of growth hormone and gonadal axes are diminished. There is also a transition from complex, sequence-dependent cognitive operations to simpler modes that, in part, represent, components of previous programs called into play during highly stressful situations. $^{14}$

Melancholic depression closely resembles the stress system phenotype. Melancholic patients have significant anxiety, mostly about their own value. They present with hyperarousal, focused attention, loss of appetite, inhibition of sexual function, decreased sleep (most often early morning awakening), anhedonia, a mood fixed in a distressed state, difficulty concentrating and inhibition of endocrine programs for growth and reproduction. ${ }^{9}$ Remitted, medication-free patients with major depression also show evidence of inflammation ${ }^{15}$ and patients with MDD have indices of increased coagulation. ${ }^{16,17}$ Conversely, atypical depression seems the inverse, and is associated with increased eating, sleep, and withdrawal, suggesting a pathological suppression of stress system activity. Our previous studies reported hyperactivity of the HPA axis in melancholia, and hypoactivity in atypical depressions in patients with seasonal affective disorder and fatigue states reviewed in the study by Gold and Chrousos ${ }^{18}$ Recently in a single, large study, Lamers et al. ${ }^{19}$ found a distinct pattern of HPA axis abnormalities and inflammatory parameters in patients with melancholic compared to those with atypical depression. Anhedonia is one feature common to both depressive subtypes.

Patients with major depression and bipolar disorder have a loss of volume in the subgenual prefrontal cortex ${ }^{20}$ consisting of glial cell loss and shrinkage of neurons. ${ }^{21}$ The subgenual prefrontal cortex assists in the assessment of the extent to which one is liable to punishment or reward, and it exerts cortical-mediated restraint on the CRH and sympathetic nervous systems. ${ }^{20}$ Chronic stress in rodents of the sort that produces depression-like symptoms causes significant regression of apical dendrites of pyramidal cells in the medial prefrontal cortex. Chronic stress in experimental animals also causes a concomitant increase in dendritic length and branching in the amygdala and the stria terminalis, complemented by studies in depressed patients showing activation of the amygdala. An activated amygdala inhibits the dopaminergic circuits of the nucleus accumbens.

Patients with MDD also have loss of volume of the hippocampus, associated with loss of neuroplasticity. The latter consists of retraction of apical dendrites, decreased neuropil and shortening of apical dendrites reviewed by Duman ${ }^{22}$ Stressed rodents that show depression-like behavioral changes show similar hippocampal changes as well as decreased neurogenesis in the dentate gyrus. ${ }^{23}$ Antidepressant medications, as well as other stimuli effective in ameliorating depression such as ECT and running reverse these changes. The restoration of neurogenesis is required for the response to antidepressants. ${ }^{24,25}$

The etiology of these mild neurodegenerative changes in depressive illness has not been definitively elucidated. Brain-derived neurotropic factor (BDNF) is one compound that has been implicated in these changes. Stress-related changes in hippocampus are associated with a reduction in BDNF. Rats bred to be heterozygous for BDNF have reduced hippocampal size. Conversely, antidepressants and ECT increase CNS BDNF, in association with an increase in neurogenesis. ${ }^{26-28}$ Conversely, stress mediators such as $\mathrm{CRH}$ produce shrinkage of hippocampal dendritic terminals. ${ }^{29}$

Stress-induced changes in the subgenual prefrontal cortex, amygdala, hippocampus and nucleus accumbens potentially contribute to the cardinal manifestations of melancholia, including increased expectation of harm, activation of the $\mathrm{CRH}$ and sympathetic nervous systems, decreased concentration, anhedonia and inhibition of growth and reproduction. Reciprocal effects of stress and treatments that ameliorate depression further support a role for stress in the etiology and natural history of MDD.

This study represents a good answer to the question, why we should not abandon genetic epidemiology and twin studies now that it is possible to conduct large-scale projects to identify specific genes involved in the susceptibility to psychiatric illness. Besides simply estimating heritability, twin studies not only allow an estimation of the role of stress in depression but have evolved to address more sophisticated questions: do liability genes have the same effects across a lifetime; how might they influence multiple disorders; how might they react to environmental risk, and, does genetics shape choices that influence the environments in which people live? Genetic epidemiology can also evaluate the extent to which liability genes influence sensitivity to a given environment, the importance of genetic and environmental factors at different stages of the disorder, and how genetic and environmental influences change across development. In addition, genetic epidemiology can be used to inform the phenotypes used in gene-finding studies, and the discipline intersects with gene identification efforts in the characterization of risk associated with various genes.

Stress in experimental animals produces antidepressant-reversible neuroanatomical changes documented in animal models of depression. A major focus of current research is to characterize molecular signaling pathways and factors that promote these effects of stress on depression, and the therapeutic effects of antidepressant treatment. In 'The road not taken: life experiences in monozygotic twin pairs discordant for major depression', Kendler and Halberstadt ${ }^{7}$ provide compelling evidence for the capacity of stress to precipitate major depression and to adversely influence its natural history. Conversely, these data support the premise that an absence of pronounced stressors confers protection from the onset of MDD.

\section{CONFLICT OF INTEREST}

The authors declare no conflict of interest.

PW Gold

National Institute of Mental Health, Bethesda, MD, USA E-mail: PhilipGold@mail.nih.gov

\section{REFERENCES}

1 Kessler RC, Kendler KS, Heath A, Neale MC, Eaves LJ. J Personality Soc Psychol 1992; 62: 257-272.

2 Wade TD, Kendler KS. Psychol Med 2000; 30: 965-974. 
3 Kendler KS, Kuhn JW, Prescott CA. Psychol Med 2004; 34: 1475-1482.

4 Keller MC, Neale MC, Kendler KS. Am J Psychiatry 2007; 164: 1521-1529 (quiz 622).

5 Kendler KS, Myers J, Halberstadt LJ. Mol Psychiatry 2011; 16: 626-633.

6 Kendler KS. Mol Psychiatry 2012; 17: 377-388.

7 Kendler KS, Halberstadt LJ. Mol Psychiatry advance online publication, 29 May 2012; doi:10.1038/mp.2012.55.

8 Kendler KS, Gardner CO. Psychol Med 2001; 31: 411-423.

9 Gold PW, Goodwin FK, Chrousos GP. N Engl J Med 1988; 319: 348-353.

10 Gold PW, Goodwin FK, Chrousos GP. N Engl J Med 1988; 319: 413-420.

11 Gold PW, Chrousos GP. Mol Psychiatry 2002; 7: 254-275.

12 Cohen S, Janicki-Deverts D, Doyle WJ, Miller GE, Frank E, Rabin BS et al. Proc Natl Acad Sci USA 2012; 109: 5995-5999.

13 von Kanel R, Mills PJ, Fainman C, Dimsdale JE. Psychosomatic Med 2001; 63: 531-544.

14 McGaugh JL. Trends Neurosci 2002; 25: 456.

15 Kling MA, Alesci S, Csako G, Costello R, Luckenbaugh DA, Bonne O et al. Biol Psychiatry 2007; 62: 309-313.

16 Horne 3rd MK, Merryman PK, Cullinane AM, Cai J, Martinez PE, Kling MA et al. Thrombosis Res 2007; 120: 517-521.
17 Eskandari F, Mistry S, Martinez PE, Torvik S, Kotila C, Sebring N et al. Metabol Clin Exp 2005; 54: 918-924.

18 Gold PW, Chrousos GP. Mol Psychiatry 2013; 18: 632-634.

19 Lamers FVN, Merikangas KR, de Jonge P, Beekman AT, Penninx BW. Mol Psychiatry 2013; 18: 692-699.

20 Drevets WC, Price JL, Simpson Jr. JR, Todd RD, Reich T, Vannier M et al. Nature 1997; 386: 824-827.

21 Rajkowska G, Miguel-Hidalgo JJ. CNS Neurol Disord Drug Targets 2007; 6: 219-233.

22 Duman RS. Dialogues Clin Neurosci 2009; 11: 239-255.

23 Dranovsky A, Hen R. Biol Psychiatry 2006; 59: 1136-1143.

24 Duric V, Duman RS. Cell. Mol Life Sci 2013; 70: 39-53.

25 Santarelli L, Saxe M, Gross C, Surget A, Battaglia F, Dulawa S et al. Science 2003; 301: 805-809.

26 Duman RS, Heninger GR, Nestler EJ. Arch Gen Psychiatry 1997; 54: 597-606.

27 Duman RS, Voleti B. Trends Neurosc 2012; 35: 47-56.

28 Schmidt HD, Duman RS. Behav Pharmacol 2007; 18: 391-418.

29 Sheng H, Xu Y, Chen Y, Zhang Y, Xu X, He C et al. Endocrine 2012; 41: 458-464. 